Marquette University

e-Publications@Marquette

College of Nursing Faculty Research and

Publications

Nursing, College of

$5-2020$

\title{
Using the Engaging Parents in Education for Discharge (ePED) iPad Application to Improve Parent Discharge Experience
}

\author{
Stacee M. Lerret \\ Medical College of Wisconsin \\ Norah L. Johnson \\ Marquette University, norah.johnson@marquette.edu \\ Michele Polfuss \\ Children's Hospital of Wisconsin \\ Marianne E. Weiss \\ Marquette University, marianne.weiss@marquette.edu \\ Karen Gralton \\ Children's Hospital of Wisconsin
}

See next page for additional authors

Follow this and additional works at: https://epublications.marquette.edu/nursing_fac

Part of the Nursing Commons

\section{Recommended Citation}

Lerret, Stacee M.; Johnson, Norah L.; Polfuss, Michele; Weiss, Marianne E.; Gralton, Karen; Klingbeil, Carol; Gibson, Cori A.; Garnier-Villarreal, Mauricio; Ahamed, Sheikh Iqbal; Adib, Riddhiman; Unteutsch, Rachel; Pawela, Louis; White-Traut, Rosemary; and Sawin, Kathleen J., "Using the Engaging Parents in Education for Discharge (ePED) iPad Application to Improve Parent Discharge Experience" (2020). College of Nursing Faculty Research and Publications. 657.

https://epublications.marquette.edu/nursing_fac/657 


\section{Authors}

Stacee M. Lerret, Norah L. Johnson, Michele Polfuss, Marianne E. Weiss, Karen Gralton, Carol Klingbeil, Cori A. Gibson, Mauricio Garnier-Villarreal, Sheikh Iqbal Ahamed, Riddhiman Adib, Rachel Unteutsch, Louis Pawela, Rosemary White-Traut, and Kathleen J. Sawin 
Marquette University

e-Publications@Marquette

\section{Nursing Faculty Research and Publications/College of Nursing}

This paper is NOT THE PUBLISHED VERSION; but the author's final, peer-reviewed manuscript. The published version may be accessed by following the link in the citation below.

Journal of Pediatric Nursing, Vol. 52 (May-June 2020): 41-48. DOI. This article is (C) Elsevier and permission has been granted for this version to appear in e-Publications@Marquette. Elsevier does not grant permission for this article to be further copied/distributed or hosted elsewhere without the express permission from Elsevier.

\section{Using the Engaging Parents in Education for Discharge (ePED) iPad Application to Improve Parent Discharge Experience}

Stacee M. Lerret

Medical College of Wisconsin, Milwaukee, WI

Children's Hospital of Wisconsin, Milwaukee, WI

Norah L. Johnson

Children's Hospital of Wisconsin, Milwaukee, WI

College of Nursing, Marquette University, Milwaukee, WI

Michele Polfuss

Children's Hospital of Wisconsin, Milwaukee, WI

College of Nursing, University of Wisconsin-Milwaukee, Milwaukee, WI

Marianne Weiss

College of Nursing, Marquette University, Milwaukee, WI

Karen Gralton

Children's Hospital of Wisconsin, Milwaukee, WI

Carol G. Klingbeil 
College of Nursing, University of Wisconsin-Milwaukee, Milwaukee, WI

\section{Cori Gibson}

Children's Hospital of Wisconsin, Milwaukee, WI

\section{Mauricio Garnier-Villarreal}

College of Nursing, Marquette University, Milwaukee, WI

\section{S. Iqbal Ahamed}

College of Nursing, Marquette University, Milwaukee, WI

\section{Riddhiman Adib}

College of Nursing, Marquette University, Milwaukee, WI

\section{Rachel Unteutsch}

Medical College of Wisconsin, Milwaukee, WI

\section{Louis Pawela}

Medical College of Wisconsin, Milwaukee, WI

\section{Rosemary White-Traut}

Children's Hospital of Wisconsin, Milwaukee, WI

\section{Kathy Sawin}

Children's Hospital of Wisconsin, Milwaukee, WI

College of Nursing, University of Wisconsin-Milwaukee, Milwaukee, WI

\section{Abstract \\ Purpose}

The purpose of this study was to evaluate the use of the Engaging Parents in Education for Discharge (ePED) iPad application on parent experiences of hospital discharge teaching and care coordination. Hypotheses were: parents exposed to discharge teaching using ePED will have 1) higher quality of discharge teaching and 2) better care coordination than parents exposed to usual discharge teaching. The secondary purpose examined group differences in the discharge teaching, care coordination, and 30-day readmissions for parents of children with and without a chronic condition.

\section{Design/Methods}

Using a quasi-experimental design, ePED was implemented on one inpatient unit $(n=211)$ and comparison group $(n=184)$ from a separate unit at a pediatric academic medical center. Patient experience outcome measures collected on day of discharge included Quality of Discharge Teaching Scale-Delivery (QDTS-D) and care coordination measured by Care Transition Measure (CTM). Thirty-day readmission was abstracted from records.

Results

Parents taught using $e$ PED reported higher QDTS-D scores than parents without $e$ PED ( $p=.002)$. No differences in CTM were found between groups. Correlations between QDTS-D and CTM were small for ePED $(r=0.14, p 0.03)$ and non-ePED $(r=0.29, p<.001)$ parent groups. CTM was weakly associated with 30-day readmissions in the ePED group. 


\section{Conclusion}

The use of $e$ PED by the discharging nurse enhances parent-reported quality of discharge teaching.

\section{Practice implications}

The ePED app is a theory-based structured conversation guide to engage parents in discharge preparation. Nursing implementation of ePED contributes to optimizing the patient/family healthcare experience.

\section{Keywords}

Pediatric, Parent, Discharge teaching, Readmission, Parent engagement, iPad application

High quality comprehensive preparation for discharge is essential for optimal recovery of children at home after hospitalization (Diaz-Caneja, Glendhill, Weaver, Nadel, \& Garralda, 2005; Institute of Medicine, 2010; Toomey et al., 2015; Lerret, 2009; Lerret and Weiss, 2011). According to the National Academy of Medicine (Institute of Medicine, 2010), a key activity for promoting the health of children is improving the discharge transition process. Nurses play a central role in discharge preparation, which involves the three inter-related processes of discharge planning, discharge coordination, and discharge teaching (Weiss et al., 2015). The 'Framework of Pediatric Hospital Discharge Care' emphasizes the importance of a conversational approach to addressing the goals, needs and plans for hospital discharge with family members involved in the care of the child at home (Berry et al., 2014).

Traditionally, discharge teaching has been unidirectional (Candela et al., 2018), with the nurse providing information to parents and instruction and/or demonstration of skills needed for home management. Tools to facilitate information transfer with parents are often limited to review of checklists, printed information and resources for who to contact for potential problems. Technology based strategies have emerged as another mechanism for parents to receive disease specific information related to their child's health care needs (Hall \& Bierman, 2015). Teach-back is now a commonly used approach to verifying patient understanding of discharge instructions (Kornburger et al., 2013; Markley et al., 2013; White, Garbez, Carroll, Brinker, \& Howie-Esquivel, 2013). Research relevant to discharge teaching has produced evidence about the content of the instruction. However, the skills of the nurses conducting discharge teaching are equally important for achieving patient and parent outcomes, including readiness for hospital discharge and preventing hospital readmission (Weiss et al., 2007; Weiss et al., 2011). In basic nursing education, preparation regarding discharge is more strongly focused on what to teach rather than teaching methods for engaging patients and families in ways that lead to retention of information, application and problem solving in the home environment (Candela, Piacentine, Bobay, \& Weiss, 2018).

Assessment of discharge teaching and care coordination needs begins on admission but is a priority as discharge nears. Discharge teaching and care coordination should include parent input and engagement (Candela et al., 2018) to identify the unique and individual needs of patients and their families (Berry et al., 2014; Toomey et al., 2015). The individuality and uniqueness of patient and family needs at hospital discharge is most critical for children with medical complexity and chronic health conditions (Berry et al., 2011; Berry et al., 2013; Lerret et al., 2015). For example, parents of 
hospitalized transplant recipients who reported being unprepared to implement hospital discharge instructions (Glick, Farkas, \& Nicholson, 2017) had difficulty managing their child's complex care needs at home (Lerret, 2009; Lerret and Weiss, 2011 ; Lerret et al., 2015).

While disease-specific guidelines are used to prepare parents for the child's medical care and treatment needs at home after discharge, little research has been conducted to establish evidencebased practices for pre-discharge teaching methods. Nurses need effective resources to assist them in the process of engaging the parent in the preparation for discharge so that it is individualized, and the parent experience of discharge is optimal. To address this gap, we developed the Engaging Parents in Education for Discharge (ePED) iPad application (app).

This study investigates the use of an interactive teaching method guided by the ePED, an innovative app, to address specific content elements of importance to family self-management at home after the child's discharge from the hospital. The goal of the ePED app was to provide a tool for the discharging nurse to facilitate the teaching methods and improve the quality of parent discharge preparation. Ultimately, improving discharge preparation should improve post-discharge outcomes including a reduction in emergency department use and hospital readmission.

The purpose of this study was to evaluate the use of ePED in preparing for hospital discharge on parent experiences of hospital discharge teaching and care coordination. There were two primary hypotheses:

(1) Parents exposed to discharge teaching using ePED will have higher quality of discharge teaching scores than parents exposed to usual discharge teaching.

(2) Parents exposed to discharge teaching using ePED will report better care coordination than parents exposed to usual discharge teaching.

A secondary purpose was to examine differences in the discharge teaching and care coordination outcomes for parents of children with and without a chronic condition and the association of discharge teaching and care coordination to readmissions within 30 days post discharge within ePED and nonePED groups. The secondary hypotheses are:

(3) Parents of children with a chronic condition will report higher quality discharge teaching and care coordination than parents of children without a chronic condition.

(4) Quality of discharge teaching and care coordination will be inversely associated with readmission within 30 days for parents who receive teaching with the app.

\section{Theoretical framework}

The program of research and specifically the discharge teaching method used in the ePED app was guided by two conceptual frameworks and a teaching method: (1) Tanner's Reflective Practitioner Theory (Tanner, 2006), (2) The Individual and Family Self-Management Theory (Ryan and Sawin, 2009) and (3) The "Teach-Back" method to support health literacy (Kemp, Floyd, McCord-Duncan, \& Lang, 2008; Peter et al., 2015). Tanner's theory proposes that reflective nurses notice problems, interpret child/family behavior, respond with appropriate action, read the family's response to nursing actions, and adjust their actions accordingly (Tanner, 2006). Integral to this process is the nurses' recognition of 
individual and family health-related values and beliefs as outlined in the Individual and Family SelfManagement Theory (IFSMT) (Ryan and Sawin, 2009). The IFSMT acknowledges the responsibility assumed by the individual and family for healthcare daily functioning and how nurses collaborate with families to help them learn the care needed for self-managing their health condition (Ryan and Sawin, 2009). Teach-Back is an educational tool that uses an iterative face-to-face approach when teaching families and asking them to recall, demonstrate or restate what they learned (Kemp et al., 2008; Peter et al., 2015; Ryan and Sawin, 2009). The Teach-back approach was extended to include "think forward", to facilitate the nurse to proactively consider or elicit potential challenges families may encounter after hospital discharge (Sawin et al., 2017). The integration of these frameworks informed the content, as well as the process for this innovative ePED teaching tool that was specifically designed to guide an interactive conversation between the parent and discharging nurse.

\section{ePED Application}

The foundation of the app was modeled after research conducted by Sawin et al., (2017) that utilized a longer conversation guide to engage parents at the time of discharge teaching (Sawin et al., 2017). The initial tool included theory-based discharge questions in the form of an iPad app for nurses to use in preparing families for discharge and self-management for their child at home (Sawin et al., 2017). The original app was the Family Self-Management Discharge Preparation Implementation (FSM-DPI) with nine domains (home care, child's care, practice, medications, watching child, recovery, child development, family adjustments, and parent support) informed by the Individual and Family SelfManagement Theory (Sawin et al., 2017). The app was piloted by nurses at a pediatric hospital on the day of hospital discharge (Weiss et al., 2017). Overall, the quality of discharge teaching was high. However, nurses involved in the study recommended a shorter version to improve feasibility for use in routine nursing practice. Based on nurse feedback, the FSM-DPI was refined from nine to five domains (1) signs and symptoms, 2) medications, 3) appointments and results, 4) recovery and 5) thinking forward to family adjustment) and renamed the Engaging Parents in Education for Discharge (ePED) app (See Fig. 1 for a sample screen from the ePED app). 
Signs and Symptoms: Watching Child

\section{Let's talk about things to watch for in the first few} days or weeks after your child is home

Tell me how you would know if your child is not doing well?

What will you watch for?
Asked
What will you do to keep track of these things?
Asked
I want to be sure that you know when to call your doctor or nurse when you go
home. Tell me what situations would make you want to call your nurse or
doctor?

\begin{tabular}{|l|l|}
\hline Asked & Not Asked \\
\hline
\end{tabular}

What worries or concerns do you have about caring for your child at home?

\begin{tabular}{|c|c|c|c|c|}
\hline Asked & Not Asked & & & \\
\hline \multicolumn{5}{|c|}{ What other questions do you have? } \\
\hline \multicolumn{5}{|c|}{ Not Asked } \\
\hline \multicolumn{5}{|c|}{ After listening to you, I think we also need to talk about... } \\
\hline \multicolumn{5}{|l|}{ PARENT RESPONSE } \\
\hline Verbalizes correct information & Incorrect/Unsure & \multicolumn{2}{|c|}{ No Understanding } & \\
\hline \multicolumn{4}{|l|}{ RN RESPONSE TO PARENT } & \multirow{6}{*}{ Next } \\
\hline Positive reinforcement & & YES & NO & \\
\hline Suplemental information & & YES & NO & \\
\hline Extensive teaching & & YES & NO. & \\
\hline Corrected information errors & & YES: & NO & \\
\hline Provide additional resources & & YES: & NO & \\
\hline
\end{tabular}

Fig. 1. Sample screen of the ePED app.

With the ePED app, the nurse focuses on understanding the risks and complexities as well as the strengths of the family in managing the child's condition and the transition between hospital and home. The outcome of highly engaged and structured discharge communication can identify risks, activate resources and reinforce parent strengths. The ePED app guides the nurse through the five domains by providing specific open-ended questions to assess, confirm, and encourage parents before going home, eliciting specific plans and potential concerns, gaps in knowledge and opportunities for additional teaching. 


\section{Methods}

\section{Design}

A quasi-experimental pre-post two group design was used to evaluate the effect of $e$ PED on parent experiences of hospital discharge measured as their perception of quality of discharge teaching and care coordination. The discharging nurse used the ePED app to guide the discharge teaching session with parents on the day of discharge, followed by collection of parent-reported measures of quality of discharge teaching and care coordination prior to hospital discharge. The non-ePED group received the current standard of care.

\section{Subjects and Sample.}

The study's convenience sample consisted of parents of hospitalized children $(n=395)$ who were preparing for discharge home from two separate units within a free-standing pediatric academic medical center with Magnet designation in the Midwestern United States. Data were collected between August 2018 and January 2019. ePED was implemented on a 24-bed surgical unit and a 24bed medical care unit served as the comparison group. Parents were included if they were 18 years of age or older, could speak and read English, and agreed to participate in the use of $e$ PED to guide discharge conversations and for data collection for the study's outcome measures. Parents were excluded if the hospitalized child was older than 18 years of age.

\section{Measures}

\section{Quality of discharge teaching}

The 18-item Quality of Discharge Teaching Scale (QDTS) is comprised of two subscales: (1) Content and (2) Delivery. To reduce participant burden, only the 12-item delivery subscale (QDTS-D) was used to measure quality discharge teaching by nurses assigned to the family throughout the hospitalization (Weiss et al., 2008). This subscale reflects the way nurses teach, not the content (Weiss et al., 2017). The delivery subscale includes items about listening to and answering specific questions and concerns, expressing sensitivity to personal beliefs and values, teaching in a manner that the parent could understand and at times that were good for parents, providing consistent information, promoting confidence in ability to care for the child and in knowing what to do in an emergency, and decreasing anxiety about going home. The Cronbach's alpha reliability for this subscale in a sample of parents of hospitalized children is high at 0.86 (Lerret and Weiss, 2011). Response categories range from "not at all" (0) to "always" (10). The scale score is reported as the mean of item scores (Weiss et al., 2008). Higher scores reflect parent's perception of receiving higher quality of discharge teaching.

\section{Care coordination}

The Care Transition Measure (CTM) is a 15-item measure with four key domains to measure care coordination (Coleman et al., 2002). The CTM was developed for the adult patients, but was adapted for use with parents of hospitalized children (Lerret and Weiss, 2011; Lerret et al., 2015). The four domains include transfer of information, preparation of patient/caregiver, self-management support, and empowerment to address preferences (Coleman et al., 2002). The tool has high Cronbach's alpha reliability estimates in adult (0.93) (Coleman, Mahoney, \& Parry, 2005) and pediatric (0.89 to 0.95) populations (Lerret and Weiss, 2011; Lerret et al., 2015). The response categories are "strongly disagree" (1) to "strongly agree" (4). Parents can also respond with a "Don't Know/Don't Remember/ 
Not Applicable". The mean score for each respondent is linearly transformed to a 0-100 scale. The total score represents the overall quality of the care transition. Lower total scale scores are indicative of a poorer quality transition where higher scores indicate a better transition (Coleman et al., 2002).

\section{Characteristics of the child and family}

A limited number of child/family characteristics obtained by parent self-report were used to describe the sample: parent age and sex, child age and sex, number of hospitalizations in previous year, type of insurance, number of medication(s) that the parent is responsible for administering post discharge and type of case (medical or surgical). The presence of a chronic condition of the child was collected by parent report from a list of chronic conditions (Table 1). Chronic condition was coded for analyses as $1=$ one or more chronic condition, or $0=$ no chronic conditions. Emergency department visits and hospital readmission within 30-days of discharge to the same pediatric medical center were abstracted from the electronic record.

Table 1. Sample characteristics.

\begin{tabular}{|l|l|l|}
\hline & $e P E D(\mathbf{n}=\mathbf{2 1 1})$ & Non-ePED (n= 184) \\
\hline & Mean, SD (range) & Mean, SD (range) \\
\hline Child age (years) & $9.18,4.83(2,21)$ & $9.73,5.02(2,20)$ \\
\hline Child gender & $\mathrm{n}(\%)$ & $\mathrm{n}(\%)$ \\
\hline Male & $114(54)$ & $84(45.7)$ \\
\hline Female & $96(45.5)$ & $98(53.2)$ \\
\hline Missing & $1(0.5)$ & $2(0.1)$ \\
\hline Child ethnicity & & \\
\hline Hispanic/Latinx & $29(13.7)$ & $21(11.4)$ \\
\hline Non-Hispanic/Latinx & $177(83.9)$ & $161(87.5)$ \\
\hline Missing & $5(2.4)$ & $2(1.1)$ \\
\hline Child race & & \\
\hline White & $143(67.8)$ & $113(61.4)$ \\
\hline Black & $43(20.4)$ & $42(22.8)$ \\
\hline Asian & $5(2.4)$ & $3(1.6)$ \\
\hline Multiple & $13(6.2)$ & $17(9.2)$ \\
\hline Native Alaskan/American & $7(3.3)$ & $5(2.7)$ \\
\hline Indian & 0 & $4(2.2)$ \\
\hline Missing & 0 & 0 \\
\hline Parent/caregiver age & $35.73,8.82(18,59)$ & $36.63,8.58,(14,64)$ \\
\hline Parent/caregiver gender & & \\
\hline Male & $35(16.6)$ & $34(18.5)$ \\
\hline Female & $174(82.5)$ & $149(81)$ \\
\hline Missing & $2(0.9)$ & $1(0.5)$ \\
\hline Parent marital status & & \\
\hline Married & $140(66.4)$ & $102(55.4)$ \\
\hline Single & $58(27.5)$ & $56(30.4)$ \\
\hline & & \\
\hline
\end{tabular}




\begin{tabular}{|c|c|c|}
\hline Divorced & $9(4.3)$ & 21 (11.4) \\
\hline Widowed & 0 & $2(1.1)$ \\
\hline Domestic partnership & $3(1.4)$ & $3(1.6)$ \\
\hline Missing & $1(0.5)$ & 0 \\
\hline \multicolumn{3}{|l|}{ Parent ethnicity } \\
\hline Hispanic/Latinx & 25 (11.8) & $14(7.6)$ \\
\hline Non-Hispanic/Latinx & $183(86.7)$ & $170(92.4)$ \\
\hline Missing & $3(1.4)$ & 0 \\
\hline \multicolumn{3}{|l|}{ Parent race } \\
\hline White & $155(73.5)$ & $128(69.6)$ \\
\hline Black & $38(18)$ & $38(20.7)$ \\
\hline Asian & $5(2.4)$ & $1(0.5)$ \\
\hline Multiple & $4(1.9)$ & $4(2.2)$ \\
\hline $\begin{array}{l}\text { Native Alaskan/American } \\
\text { Indian }\end{array}$ & 0 & $5(2.7)$ \\
\hline Missing & $9(4.3)$ & $8(4.3)$ \\
\hline \multicolumn{3}{|l|}{ Reason for hospitalization } \\
\hline Surgical & $165(78.2)$ & $19(10.3)$ \\
\hline Medical & $46(21.8)$ & $165(89.7)$ \\
\hline Missing & 0 & $1(0.5)$ \\
\hline \multicolumn{3}{|l|}{ Chronic conditions } \\
\hline Asthma & $28(13.4)$ & $47(26.3)$ \\
\hline Blood disorder & $0(0)$ & $2(1.1)$ \\
\hline Cancer & $2(0.9)$ & $0(0)$ \\
\hline Congenital heart disease & $8(3.8)$ & $7(3.9)$ \\
\hline Diabetes & $2(0.9)$ & $27(15.1)$ \\
\hline Gastrointestinal disorder & $16(7.7)$ & $34(18.9)$ \\
\hline Kidney disease & $5(2.4)$ & $1(0.6)$ \\
\hline Liver disease & $2(0.9)$ & $1(0.6)$ \\
\hline Neurological disease & $10(4.8)$ & $16(8.9)$ \\
\hline Rheumatological disorder & $1(0.5)$ & $2(1.1)$ \\
\hline Scoliosis & $7(3.3)$ & $7(3.9)$ \\
\hline Other & $17(8.1)$ & $28(15.6)$ \\
\hline \multicolumn{3}{|l|}{ Chronic condition (grouped) } \\
\hline 0 (none) & $115(54.5)$ & $50(27.2)$ \\
\hline 1 or more & 96 (45.5) & $134(72.8)$ \\
\hline \multicolumn{3}{|l|}{ Utilization } \\
\hline Readmission within 30 days & $10(4.7)$ & $13(7.0)$ \\
\hline
\end{tabular}




\section{Procedures}

Approval was obtained from the Institutional Review Board of the study hospital. Eligible participants received an information sheet regarding study related procedures from the bedside nurse. The study was deemed no more than minimal risk and received IRB approval with a waiver to obtain signed consent. Data were collected on the day of hospital discharge and by electronic records abstraction at 30 days post-discharge. Nurses on the implementation unit received training in use of the ePED app via an online module and in collection of the parent-reported measures. Comparison unit nurses were trained in collection of parent-reported measures only.

The inpatient nurses on both the implementation and comparison units explained the project to families on the day of discharge. Families who agreed to participate received instruction from the nurses for completing parent experience questionnaires (QDTS-D, CTM) on the study-provided iPad. The questionnaires were completed independently by the parent before hospital discharge. Upon completion of the questionnaires, parents closed the survey on the iPad and returned the iPad to a member of the inpatient staff. Clinical nurses on the implementation unit executed and documented use of the ePED app during hospital discharge education.

The data from the ePED app was entered via the iPad into a REDCap database by the nurse. Child and parent demographics as well as parent experience questionnaires were entered via the iPad by the parent into a REDCap database. Utilization data, ED visit and readmission in the first 30-days following hospital discharge, was collected by the designated study team research coordinator via medical record abstraction.

\section{Data analysis}

The analyses were performed in the platform R (R Core Team, 2019). Descriptive statistics were used to describe the sample and compare between ePED implementation and non-ePED comparison units. The Cronbach alpha $(\alpha)$ was used to assess the reliability of the QDTS-D and CTM scales in the study population. For continuous outcomes, we used General Linear Models (GLM) that included $t$-tests. The significance level was set at $p<0.05$. $t$-Tests were performed to identify if there was a mean difference in the QDTS-D and the CTM between parents of the children from implementation who received teaching guided by the ePED app and parents of children from the comparison unit who did not receive teaching guided by the ePED. Because of the differences in types of patients on the implementation (surgical case types) and comparison (medical case types) units, we examined differences between patients with and without chronic conditions within each unit (ePED implementation and non-ePED comparison) separately, rather than comparing across units; $t$-tests were used to examine these differences. For the same reason, we examined the relationship of QDTS-D and CTM with subsequent readmission within 30 days post-discharge using logistic regression for parents/patients discharged from ePED and non-ePED units separately.

\section{Results}

Our sample included 211 parents from the ePED implementation unit and 184 parents from the comparison unit. Parents were primarily female (82\%) and married (61\%) with a mean age of 36.18 years $(S D=8.70)$. Child sex was evenly distributed between male $(49 \%)$ and female $(51 \%)$ with a mean age of 9.46 years $(S D=4.93)$. Additional characteristics are detailed in Table 1. 
The Cronbach alpha (Cronbach, 1951) was used to assess the inter-item correlation, and McDonald's Omega (McDonald, 1999) was used to assess reliability of the QDTS-D and CTM scales in the study population (Raykov, 2012). Both QDTS-D and CTM scales had high Cronbach's alpha inter-item correlation estimates in this sample $(\alpha=0.91$ and $\alpha=0.98)$, and high McDonald's Omega reliability ( $\omega=0.91$ and $\omega=0.97$ ). Scale scores for parents with both ePED and non-ePED were skewed near the high end of both scales. QDTS-D scores exceeded 9 out of 10 for the entire sample (mean $=9.48, S D=0.84)$, indicating very high-quality teaching. CTM scores were also near the upper end of the scale (mean $=3.77, S D=0.55$ ) indicating positive parent reports of transitional care coordination.

Testing of the primary hypotheses evaluated differences between parents exposed to $e P E D$ and parents receiving usual discharge teaching on the parent's discharge experience, specifically their perceptions of the quality of discharge teaching (hypothesis 1 ) and care coordination (hypothesis 2). QDTS-D scores were significantly higher for parents exposed to the ePED app (mean $=9.59, S D=0.65$ ) than parents not exposed to the app (mean $=9.33, S D=1.0, p=0.002$ ), though effect size (Cohen $d$ ) was small $(d=0.32)$. CTM scores were not statistically different between parent groups ( mean $=3.77, S D=0.60$ for $e P E D$, and mean $=3.74, S D=0.49$ for non-ePED parents). $t$-Test results are provided in Table 2. Parents with higher QDTS-D tended to score higher on CTM, though the correlations were small for the ePED parent group $(r=0.14, p=0.03)$ and in the non-ePED group $(r=0.29, p<0.001)$.

Table 2. Comparison of parent experience outcomes for ePED and non-ePED Parent Groups.

\begin{tabular}{|l|l|l|l|}
\hline & $\begin{array}{l}\text { ePED group } \\
\text { Mean (SD) } \\
\text { Range }\end{array}$ & $\begin{array}{l}\text { Non-ePED group } \\
\text { Mean (SD) } \\
\text { Range }\end{array}$ & $\begin{array}{l}\text { Test Statistics (t-test) } \\
t, d f, p, d\end{array}$ \\
\hline QDTS-D & $9.59(0.65)$ & $9.33(1.0)$ & $-3.09,306.1,0.002,0.32$ \\
& $4.0,10$ & $4.8,10$ & \\
\hline CTM & $3.77(0.60)$ & $3.74(0.49)$ & $-0.58,385.4,0.56,0.05$ \\
& 1,4 & 1,4 & \\
\hline
\end{tabular}

Note. Quality of discharge teaching scale delivery (QDTS-D), ${ }^{22}$ care transition measure (CTM) ${ }^{23}$.

Hypotheses 3 evaluated the differences in QDTS-D and CTM for parents of children with and without chronic conditions within ePED and non-ePED groups. There were no statistically significant differences identified between ePED and non-ePED groups or between chronic and non-chronic participants (Table $3)$.

Table 3. Parent experience outcomes (QDTS-D and CTM) for parents of children with and without a chronic condition.

\begin{tabular}{|l|l|l|l|l|l|}
\hline $\mathrm{g}$ & & $\begin{array}{l}\text { ePED parent } \\
\text { group }\end{array}$ & $\begin{array}{l}\text { Non-ePED } \\
\text { parent group }\end{array}$ & & \\
\hline $\begin{array}{l}\text { Parent } \\
\text { Experience } \\
\text { Outcome }\end{array}$ & $\begin{array}{l}\text { Child has Chronic } \\
\text { Condition(s) }\end{array}$ & Mean, SD & $\begin{array}{l}\text { Test statistics } \\
t, d f, p, d\end{array}$ & Mean, SD & $\begin{array}{l}\text { Test statistics } \\
t, d f, p, d\end{array}$ \\
\hline
\end{tabular}




\begin{tabular}{|l|l|l|l|l|l|}
\hline QDTS-D & Yes & $9.53,0.56$ & $1.31,202.6$, & 9.28, & $1.09,108.3$, \\
& No & $9.65,0.72$ & $0.19,0.18$ & $\begin{array}{l}1.05 \\
9.45,\end{array}$ & $0.28,0.16$ \\
& & & & 0.83 & \\
\hline CTM & Yes & $3.73,0.70$ & $0.82,167.7$, & 3.77, & $-1.05,64.2$, \\
& No & $3.80,0.50$ & $0.41,0.12$ & 0.43 & $0.29,0.21$ \\
& & & & 3.67, & \\
& & & & 0.63 & \\
\hline
\end{tabular}

Note. QDTS-D: Quality of Discharge Teaching Scale Delivery, ${ }^{22}$ CTM: Care Transition Measure ${ }^{23}$.

For hypothesis 4, logistic regression was used to evaluate QDTS-D, CTM and chronic condition as predictors for one or more readmission for each ePED and non-ePED groups separately (Table 4). For the $e P E D$ group, controlling for other predictors in the model, the strongest and only significant predictor of readmission was the CTM score. As CTM increases by one point (on a 4-point scale), the chance of having at least one readmission decreases by $55 \%(O R=0.45)$. None of the three predictor variables made a unique statistically significant contribution to the model for readmission in the nonePED group.

Table 4. Logistic regression of 30-day readmission on QDTS-D, CTM, and Chronic Condition for ePED and non-ePED parent groups.

\begin{tabular}{|l|l|l|l|l|}
\hline Implementation group & Predictors & Slope (SE) & $\boldsymbol{p}$-value & OR (95\% Cl) \\
\hline ePED & (Intercept) & $-1.04(4.85)$ & 0.83 & $0.35(0.00,506.8)$ \\
\hline & QDTS-D & $0.07(0.49)$ & 0.88 & $1.08(0.51,3.67)$ \\
\hline & CTM & $-0.80(0.32)$ & 0.01 & $0.45(0.24,0.89)$ \\
\hline & Chronic condition & $0.69(0.66)$ & 0.29 & $1.99(0.56,7.98)$ \\
\hline & (Intercept) & $-7.14(3.71)$ & 0.05 & $0.0008(0.00,0.37)$ \\
\hline & QDTS-D & $0.36(0.36)$ & 0.32 & $1.43(0.79,3.30)$ \\
\hline & CTM & $0.16(0.63)$ & 0.80 & $1.17(0.43,5.80)$ \\
\hline & Chronic condition & $1.29(0.77)$ & 0.09 & $3.65(0.98,23.88)$ \\
\hline
\end{tabular}

Note. QDTS-D: Quality of Discharge Teaching Scale Delivery, CTM: Care Transition Measure.

\section{Discussion}

The ePED app was developed to enhance the ability of the nurse to provide optimal discharge teaching to parents of hospitalized children by engaging parents at the time of discharge. The app includes aspects of "think-forward" teaching, assesses parental knowledge, skills and abilities, and guides the nurse to provide appropriate and individualized responses to the family (i.e. positive reinforcement, further teaching, additional resources, etc.) (Sawin et al., 2017). The purpose of this study was to evaluate outcomes of the use of ePED with parents of hospitalized children on two pediatric inpatient units.

The results of the study support the positive influence that the use of the ePED had on the quality of discharge teaching. While parents rated the quality of discharge teaching delivery as high using both $e P E D$ and usual care (non-ePED) discharge teaching methods, it was higher for parents who 
received discharge teaching with the ePED app. This finding provides evidence of room for improvement even in hospital environments where quality of discharge teaching is well-rated by parents. Use of ePED in hospitals with different acuity levels of pediatric care or without Magnet status may result in wider variability of discharge teaching scores. Optimizing the patient/family experience (Shermont, Pignataro, Humphrey, \& Bukoye, 2016; Wood et al., 2017) is a priority for healthcare systems in the current era of performance measurement and value-based care, yet nurses often feel unprepared to teach (Lahl, Modic, \& Siedlecki, 2013). Having the ePED app available to facilitate discharge teaching provides a structure to assist the nurse in applying evidence-based teaching strategies that promotes the nurse's confidence as an effective teacher. The use of the ePED app holds promise for use in fostering engagement with parents, which is an essential extension of the trusting relationship that develops through the interactive teaching-learning process (Association, $A$. N, 2016; Leslie \& Lonneman, 2016).

The parent perception of care coordination was not significantly different between the parents receiving ePED instruction and usual care discharge teaching. A potential explanation may be the timing of administration of the CTM and the wording of the questions. The wording on the CTM limits the parent's reflection to the day of discharge. Care coordination plans typically take place throughout the hospitalization; thus, the parent response may not be reflective of all care coordination efforts. Future enhancements to the ePED app may include expansions to more clearly address care coordination efforts. Although typically administered post discharge, in this study, the CTM was completed by the parents prior to leaving the hospital (Coleman et al., 2002). Perceptions of the transition in care from hospital to home may change as the post-discharge realities are experienced. Furthermore, the sample of chronic condition patients enrolled in this study had a broad range of diagnoses and the reason for admission that may or not have been related to the chronic condition. In subsequent studies it will be important to link the reason for readmission to the underlying chronic condition to better understand parent's perception of the care coordination experience.

As in prior studies (Lerret and Weiss, 2011; Lerret et al., 2015), parents with higher QDTS-D scores had higher CTM scores, though the correlations were weak. There are some similarities in item domains including signs and symptoms, medications, appointments and recovery. The fact that the ePED impacted QDTS-D but not CTM suggests that improving care coordination requires a different approach than improving discharge teaching and involves other disciplines. It is also notable that the measures were reliable in this patient population, similar to previous use of the measures in pediatric discharge studies (Lerret and Weiss, 2011; Berry et al., 2014). Both the quality of discharge teaching and care coordination are factors associated with adverse experiences following discharge including readmission in several studies (Auger et al., 2015; Auger, Kenyon, Feudtner, \& Davis, 2014; Weiss et al., 2008). In some cases, readmission may be avoided with appropriate discharge preparation that includes empowering and educating the family on proper care and necessary monitoring after leaving the hospital. Reducing hospital readmissions reduces healthcare cost especially in children with chronic and complex health conditions (Kornburger, Gibson, Sadowski, Maletta, \& Klingbeil, 2013; Markley et al., 2013). The ePED app assists the nurse to identify and teach to the unique and individual needs of patients and their families, which is the recommended approach for improving parent engagement (Diaz-Caneja et al., 2005; Toomey et al., 2015; Lerret, 2009; Lerret et al., 2014). Moreover, the app 
moves patient education forward beyond a unidirectional information approach to an individualized, interactive engagement in preparing for discharge.

The design of the study using a surgical and a medical unit as the implementation and comparison units respectively did not allow for evaluation of the impact of the ePED on readmissions, as the two units represented different patient populations with high variation in diagnosis, reason for hospitalization, and rates of readmission. Examining the relationships of the parent experience measures of quality of discharge teaching and care coordination within the ePED and non-ePED groups, CTM was a significant predictor of likelihood of readmission in the ePED group only. Care transition interventions are important aspects of care and readmission avoidance in families with a child with a complex chronic condition (Lerret et al., 2015; Weiss et al., 2017).

This study has several limitations. The cross-sectional study design precluded evaluation of change over time, which would have enhanced the comparison of outcomes. The sample represented one medical and one surgical unit at a single pediatric hospital, precluding comparisons on important outcomes for healthcare utilization. These units were chosen as they had the resources to support the study-related procedures. Inclusion of a wider variety of patients would provide larger variability in the sample and increase the generalizability of the results. As typical with pediatric research, more mothers than fathers participated in the study. We were not able to collect information on the characteristics such as years of experience of the nurses that used the ePED app. The level of experience or years of working as a RN may have an influence on the nurse's skill and/or confidence with discharge teaching. The nurse characteristics should be included in future studies. Training for the comparison unit nurses regarding collection of family experience data (quality of discharge teaching and care coordination) may have influenced the study results by increasing the nurse's awareness of discharge needs and importance of discharge preparation and by stimulating the nurses to improve discharge preparation even though they were not using the ePED app. A potential source of bias is that the inpatient clinical nurse who completed the intervention was the assigned nurse for the day. Even though the parent completed the survey independently, the responses may have reflected the parent perspective of the individual nurse in addition to their response to use of ePED. Alternatively, the QDTS-D and CTM measure parent experience during the entire hospitalization and may not only reflect on the use of the ePED app. These issues will need to be clarified in a larger intervention study.

\section{Conclusions}

Healthcare systems are complex, and nurses play an integral role in the patient's experience from admission to discharge. The outcomes of this study indicate the importance of engaging parents in teaching using a theory-based structured conversation guide such as the ePED app. Quality of discharge teaching delivery was higher for parents who participated in the interactive discharge teaching process, guided by the ePED app. This novel practice innovation aligns with health system priorities for engaging patient and families in their care and optimizing the patient/family experience. The results of this study are foundational for future efforts to improving the quality of discharge education using an innovative app, family engagement and discharge experience, and mitigating postdischarge risks for adverse child outcomes. 
Enhancements are needed to better understand the role of the ePED app used by nurses during discharge education with families. Refinement of the ePED app needs to clearly address teaching needs related to care coordination. The concept of care coordination should be explored further to focus on populations with complex and/or chronic conditions. Future work may also include the integration of parent-reported experience and other outcomes including quality of life. All these enhancements in a larger trial will contribute to improving the discharge experience and optimal use of healthcare resources.

\section{CRediT authorship contribution statement}

Stacee M. Lerret: Conceptualization, Methodology, Software, Validation, Formal analysis, Investigation, Resources, Data curation, Writing - original draft, Writing - review \& editing, Visualization, Supervision, Project administration, Funding acquisition. Norah L.

Johnson: Conceptualization, Methodology, Software, Validation, Formal analysis, Investigation, Resources, Data curation, Writing - original draft, Writing - review \& editing, Visualization, Funding acquisition. Michele Polfuss: Validation, Formal analysis, Investigation, Writing - original draft, Writing - review \& editing, Visualization. Marianne Weiss: Conceptualization, Methodology, Software, Validation, Formal analysis, Investigation, Resources, Writing - original draft, Writing - review \& editing, Visualization, Funding acquisition. Karen Gralton: Conceptualization, Methodology, Software, Validation, Investigation, Resources, Writing - original draft, Writing - review \& editing, Visualization, Supervision. Carol G. Klingbeil: Conceptualization, Methodology, Software, Validation, Investigation, Resources, Writing - original draft, Writing - review \& editing, Visualization, Supervision. Cori Gibson: Conceptualization, Methodology, Software, Validation, Investigation, Resources, Writing original draft, Writing - review \& editing, Visualization, Supervision. Mauricio Garnier-

Villarreal: Conceptualization, Methodology, Validation, Formal analysis, Investigation, Data curation, Writing - original draft, Writing - review \& editing, Visualization, Project administration, Funding acquisition. S. Iqbal Ahamed: Conceptualization, Methodology, Software, Validation, Formal analysis, Investigation, Data curation, Writing - original draft, Writing - review \& editing, Visualization, Project administration, Funding acquisition. Riddhiman Adib: Software, Formal analysis, Investigation, Data curation, Writing - original draft, Writing - review \& editing, Visualization. Rachel

Unteutsch: Investigation, Resources, Data curation, Writing - original draft, Writing - review \& editing, Visualization. Louis Pawela: Investigation, Resources, Data curation, Writing - original draft, Writing review \& editing, Visualization. Rosemary White-Traut: Conceptualization, Methodology, Software, Validation, Formal analysis, Investigation, Resources, Writing - original draft, Writing - review \& editing, Visualization, Supervision, Funding acquisition. Kathy Sawin: Conceptualization, Methodology, Software, Validation, Formal analysis, Investigation, Resources, Writing - original draft, Writing - review \& editing, Visualization, Supervision, Funding acquisition.

\section{Acknowledgments}

We would like to acknowledge the following for their contribution and support: Tess Weinkauf, Amanda King, Brenna McGinn, Kari Bogdan, Unit nurses; Children's Hospital of Wisconsin operational support of Chief Nursing Officer and Vice President Nancy Korom and Vice President Lisa Jentsch. 


\section{Funding}

This work was supported by the CTSI Pilot Collaborative Clinical and Translational Research Grants Program National Center for Advancing Translational Sciences (NCATS), National Institutes of Health (NIH), Award Number UL1TR001436. Additional funds were provided by the Pediatric Nursing Research Consortium, a joint project of Children's Hospital of Wisconsin, University of Wisconsin Milwaukee College of Nursing and Marquette University College of Nursing.

\section{References}

Association, A. N, 2016. Association, A. N. Nurses rank \#1 most trusted profession for 15th year in a row http://www.nursingworld.org/FunctionalMenuCategories/MediaResources/PressReleases/201 6-News-Releases/Nurses-Rank-1-Most-Trusted-Profession-2.pdf (2016)

Auger et al., 2014. K.A. Auger, C.C. Kenyon, C. Feudtner, M.M. Davis. Pediatric hospital discharge interventions to reduce subsequent utilization: A systematic review. Journal of Hospital Medicine, 9 (4) (2014, Apr), pp. 251-260, 10.1002/jhm.2134

Auger et al., 2015. K.A. Auger, T.D. Simon, D. Cooperberg, J. Gay, D.Z. Kuo, M. Saysana, ..., M.W. Shen. Summary of STARNet: seamless transitions and (re) admissions network. Pediatrics, 135 (1) (2015, Jan), pp. 164-175, 10.1542/peds.2014-1887

Berry et al., 2014. J.G. Berry, K. Blaine, J. Rogers, S. McBride, E. Schor, J. Birmingham, ..., C. Feudtner. A framework of pediatric hospital discharge care informed by legislation, research, and practice. JAMA Pediatrics, 168 (10) (2014, Oct), pp. 955-962. quiz 965-956. https://doi.org/10.1001/jamapediatrics.2014.891

Berry et al., 2011. J.G. Berry, D.E. Hall, D.Z. Kuo, E. Cohen, R. Agrawal, C. Feudtner, ..., J. Neff. Hospital utilization and characteristics of patients experiencing recurrent readmissions within children's hospitals. JAMA, 305 (7) (2011, Feb 16), pp. 682-690, 10.1001/jama.2011.122

Berry et al., 2013.

J.G. Berry, S.L. Toomey, A.M. Zaslavsky, A.K. Jha, M.M. Nakamura, D.J. Klein, ..., M.A. Schuster. Pediatric readmission prevalence and variability across hospitals. JAMA, 309 (4) (2013, Jan 23), pp. 372-380, 10.1001/jama.2012.188351

Candela et al., 2018. L. Candela, L.B. Piacentine, K.L. Bobay, M.E. Weiss. Teaching students to teach patients: A theory-guided approach .Journal of Nursing Education and Practice, 8 (11) (2018), 10.5430/jnep.v8n11p92

Coleman et al., 2005. E.A. Coleman, E. Mahoney, C. Parry. Assessing the quality of preparation for post-hospital care from the patient's perspective: The care transitions measure. Medical Care, 43 (3) (2005), pp. 246-255

Coleman et al., 2002. E.A. Coleman, J.D. Smith, J.C. Frank, T.B. Eilertsen, J.N. Thiare, A.M. Kramer. Development and testing of a measure designed to assess the quality of care transitions. International Journal of Integrated Care, 2 (1) (2002), pp. 1-9

Cronbach, 1951. L.J. Cronbach. Coefficient alpha and the internal structure of tests. Psychometrika, 16 (3) (1951), pp. 297-334

Diaz-Caneja et al., 2005. A. Diaz-Caneja, J. Glendhill, T. Weaver, S. Nadel, E. Garralda. A child's admission to hospital: A qualitative study examining the experiences of parents. Intensive Care Medicine, 31 (2005), pp. 1248-1254

Glick et al., 2017. A.F. Glick, J.S. Farkas, J. Nicholson. Parental management of discharge instructions: A systematic review. Pediatrics, 140 (2) (2017) 
Hall and Bierman, 2015. C.M. Hall, K.L. Bierman. Technology-assisted interventions for parents of young children: Emerging practices, current research, and future directions. Early Child Research Quarterly, 33 (2015), pp. 21-32, 10.1016/j.ecresq.2015.05.003

Institute of Medicine, 2010. Institute of Medicine. The future of nursing: Leading change, advancing health. The National Academies Press, Washington, D.C (2010)

Kemp et al., 2008. E.C. Kemp, M.R. Floyd, E. McCord-Duncan, F. Lang. Patients prefer the method of

"tell back-collaborative inquiry" to assess understanding of medical information. Journal of American Board of Family Medicine, 21 (1) (2008, Jan-Feb), pp. 24-

30, 10.3122/jabfm.2008.01.070093

Kornburger et al., 2013. C. Kornburger, C. Gibson, S. Sadowski, K. Maletta, C. Klingbeil. Using "teachback" to promote a safe transition from hospital to home: An evidence-based approach to improving the discharge process. Journal of Pediatric Nursing, 28 (3) (2013, May-Jun), pp. 282291, 10.1016/j.pedn.2012.10.007

Lahl et al., 2013. M. Lahl, M.B. Modic, S. Siedlecki. Perceived knowledge and self-confidence of pediatric nurses as patient educators. Clinical Nurse Specialist, 27 (4) (2013, Jul-Aug), pp. 188193, 10.1097/NUR.0b013e3182955703

Lerret, 2009. S.M. Lerret. Discharge readiness: an integrative review focusing on discharge following pediatric hospitalization. Journal for Specialists in Pediatric Nursing, 14 (4) (2009), pp. 245255, 10.1111/j.1744-6155.2009.00205.x

Lerret and Weiss, 2011. S.M. Lerret, M.E. Weiss. How ready are they? Parents of pediatric solid organ transplant recipients and the transition from hospital to home following transplant. Pediatric Transplantation, 15 (6) (2011), pp. 606-616, 10.1111/j.1399-3046.2011.01536.x

Lerret et al., 2014.

S.M. Lerret, M.E. Weiss, G. Stendahl, S. Chapman, K. Neighbors, K. Amsden, ..., E.M. Alonso. Transition from hospital to home following pediatric solid organ transplant: qualitative findings of parent experience. Pediatric Transplantation, 18 (5) (2014), pp. 527-

537, 10.1111/petr.12269

Lerret et al., 2015.

S.M. Lerret, M.E. Weiss, G.L. Stendahl, S. Chapman, J. Menendez, L. Williams, ..., P. Simpson.

Pediatric solid organ transplant recipients: transition to home and chronic illness care.

Pediatric Transplantation, 19 (1) (2015), pp. 118-129, 10.1111/petr.12397

Leslie and Lonneman, 2016. J.L. Leslie, W. Lonneman. Promoting Trust in the Registered Nurse-Patient

Relationship. Home Healthc Now, 34 (1) (2016, Jan), pp. 38-

42, 10.1097/NHH.0000000000000322

Markley et al., 2013. J. Markley, V. Andow, K. Sabharwal, Z. Wang, E. Fennell, R. Dusek. A project to reengineer discharges reduces 30-day readmission rates. American Journal of Nursing, 113 (7) (2013), pp. 55-64, 10.1097/01.naj.0000431922.47547.eb

McDonald, 1999. R.P. McDonald. Test theory: A unified treatment. Erlbaum (1999)

Peter et al., 2015. D. Peter, P. Robinson, M. Jordan, S. Lawrence, K. Casey, D. Salas-Lopez. Reducing readmissions using teach-back: Enhancing patient and family education. The Journal of Nursing Administration, 45 (1) (2015, Jan), pp. 35-42, 10.1097/NNA.0000000000000155

R Core Team, 2019. R Core Team (2019). R: A language and environment for statistical computing. $R$ Foundation for Statistical Computing, V., Austria. URL https://www.R-project.org/. (2019). R: A language and environment for statistical computing. https://www.R-project.org/.

Raykov, 2012. T. Raykov. Scale construction and development using structural equation modeling.

R.H. Holye (Ed.), Handbook of structural equation modeling, Guilford (2012), pp. 472-494 
Ryan and Sawin, 2009. P. Ryan, K.J. Sawin. The Individual and Family Self-Management Theory: background and perspectives on context, process, and outcomes. Nursing Outlook, 57 (4) (2009), pp. 217-225.e216, 10.1016/j.outlook.2008.10.004

Sawin et al., 2017.

K.J. Sawin, M.E. Weiss, N. Johnson, K. Gralton, S. Malin, C. Klingbeil, ..., R.F. Schiffman.

Development of a Self-Management Theory-Guided Discharge Intervention for Parents of Hospitalized Children. Journal of Nursing Scholarship, 49 (2) (2017), pp. 202-

213, 10.1111/jnu.12284

Shermont et al., 2016. H. Shermont, S. Pignataro, K. Humphrey, B. Bukoye. Reducing pediatric readmissions: Using a discharge bundle combined with teach-back methodology. Journal of Nursing Care Quality, 31 (3) (2016, Jul-Sep), pp. 224-232, 10.1097/NCQ.0000000000000176

Tanner, 2006. C.A. Tanner. Thinking like a nurse: A research-based model of clinical judgment in nursing. Journal of Nursing Education, 45 (6) (2006), pp. 204-211

Toomey et al., 2015.

S.L. Toomey, A.M. Zaslavsky, M.N. Elliott, P.M. Gallagher, F.J. Fowler Jr., D.J. Klein, ..., M.A. Schu ster. The development of a pediatric inpatient experience of care measure: Child HCAHPS. Pediatrics, 136 (2) (2015, Aug), pp. 360-369, 10.1542/peds.2015-0966

Weiss et al., 2007. M.E. Weiss, L.B. Piacentine, L. Lokken, J. Ancona, J. Archer, S. Gresser, ..., T. VegaStromberg. Perceived readiness for hospital discharge in adult medical-surgical patients. Clinical Nurse Specialist, 21 (1) (2007), pp. 31-42

Weiss et al., 2008. M. Weiss, N.L. Johnson, S. Malin, T. Jerofke, C. Lang, E. Sherburne. Readiness for discharge in parents of hospitalized children. Journal of Pediatric Nursing, 23 (4) (2008), pp. 282-295, 10.1016/j.pedn.2007.10.005

Weiss et al., 2011. M.E. Weiss, O. Yakusheva, K.L. Bobay. Quality and cost analysis of nurse staffing, discharge preparation, and postdischarge utilization. Health Services Research, 46 (5) (2011), pp. 1473-1494, 10.1111/j.1475-6773.2011.01267.x

Weiss et al., 2015. M.E. Weiss, K.L. Bobay, S.J. Bahr, L. Costa, R.G. Hughes, D.E. Holland. A model for hospital discharge preparation: From case management to care transition. The Journal of Nursing Administration, 45 (12) (2015), pp. 606-614, 10.1097/NNA.0000000000000273

Weiss et al., 2017. M.E. Weiss, K.J. Sawin, K. Gralton, N. Johnson, C. Klingbeil, S. Lerret, ..., R. Schiffman. Discharge Teaching, Readiness for Discharge, and Post-discharge Outcomes in Parents of Hospitalized Children. Journal of Pediatric Nursing, 34 (2017), pp. 5864, 10.1016/j.pedn.2016.12.021

White et al., 2013. M. White, R. Garbez, M. Carroll, E. Brinker, J. Howie-Esquivel. Is "teach-back" associated with knowledge retention and hospital readmission in hospitalized heart failure patients? Journal of Cardiovascular Nursing, 28 (2013), pp. 137-146.

(doi:10.1097.jcn.0b013e31824987bd)

Wood et al., 2017.

E.B. Wood, G. Harrison, A. Trickey, M.A. Friesen, S. Stinson, E. Rovelli, ..., K. Presgrave. Evidence-based practice: Video-discharge instructions in the pediatric emergency department. Journal of Emergency Nursing, 43 (4) (2017, Jul), pp. 316321, 10.1016/j.jen.2016.11.003 